\title{
IMPLEMENTASI KEBIJAKAN JAMINAN KESEHATAN BAGI MASYARAKAT MISKIN DI KABUPATEN PATI
}

\section{THE POLICY IMPLEMENTATION OF HEALTH INSURANCE FOR THE POOR IN PATI REGENCY}

\author{
Suroso \\ Badan Perencanaan Pembangunan Daerah Kabupaten Pati \\ Email: suroso_peneliti@yahoo.co.id
}

\begin{abstract}
Health insurance payment for the poor is mandated in Indonesian laws. The objectives of the research is to analyze coverage and distribution of health insurance payment for the poor. This research uses descriptive-quantitative approach. There are two variables in the research: (1) coverage of health insurance payment for the poor; and (2) distribution of health insurance payment. Data collecting is conducted by observing documents and interviews. The data analysis uses descriptive and correlative one. This research has thee main findings. Firstly, the coverage of health insurance payment for the poor in Pati Regency has ratio coverage 1.95 (195\%), fulfilling for adequacy. Secondly, there is a gap among districts for the coverage of health insurance payment for the poor in which the biggest ratio coverage 3.01 (301\%) and the smallest ratio coverage 0.90 (90\%). Thirdly, distribution equity of health insurance payment is relatively poor which is shown by Spearman Rank Correlation having Rho value 0.226 less than Rho table value (0.439). It means that there is no correlation between the needs of health insurance payments for the poor and the recievers of health insurance payments for each district.
\end{abstract}

Keywords: coverage, distribution, health insurance

\section{ABSTRAK}

Bantuan iuran jaminan kesehatan merupakan amanat perundang-undangan di Indonesia. Penelitian ini memiliki tujuan untuk menganalisa cakupan dan distribusi bantuan iuran jaminan kesehatan bagi penduduk miskin di Kabupaten Pati. Penelitian ini menggunakan pendekatan deskriptif-kuantitatif. Ada 2 variabel dalam penelitian: (1) coverage bantuan iuran jaminan kesehatan bagi penduduk miskin ;dan (2) distribusi penerima bantuan iuran (PBI) jaminan kesehatan. Pengumpulan data dilakukan dengan menggunakan teknik observasi dokumen dan wawancara. Analisa data menggunakan analisis deskriptif dan korelatif. Penelitian ini memiliki 3 temuan. Pertama, coverage bantuan iuran jaminan kesehatan bagi penduduk miskin di Kabupaten Pati memenuhi batas kecukupan minimal dengan status ratio coverage 1,95 (195\%). Kedua, coverage bantuan iuran jaminan kesehatan anatar kawasan mengalami timpangan dengan ratio coverage terbesar 3,01 (301\%) dan ratio coverage terkecil 0,90 (90\%). Ketiga, keadilan distribusi bantuan iuran jaminan kesehatan relatif kurang baik yang ditunjukkan uji statistik Spearman Rank Correlation dengan nilai Rho hitung $(0,226)$ lebih kecil dari nilai Rho tabel $(0,439)$ yang berarti tidak ada kesesuaian antara tingkat kebutuhan bantuan iuran jaminan kesehatan bagi penduduk miskin dengan penerima bantuan iuran (PBI) jaminan kesehatan.

Kata kunci: cakupan, distribusi, jaminan kesehatan 


\section{PENDAHULUAN}

Pembangunan kesehatan merupakan amanat pembangunan global dan nasional. Pembangunan kesehatan secara global diantaranya diamanatkan dalam Millenium Development Goals (UN, 2000) dan World Health Assembly (WHO, 2005) yang diselenggarakan di Geneva. Millennium Declaration Tahun 2000 disepakati komitmen pembangunan global yang dikenal dengan "Millenium Development Goals (MDG's).

Resolusi WHO ke 58 Tahun 2005 di Genewa mengamanatkan setiap negara perlu mengembangkan Universal Health Coverage (UHC) melalui mekanisme asuransi kesehatan sosial untuk menjamin pembiayaan kesehatan yang berkelanjutan. Resolusi ini sering dikonotasikan "Health for all" (kesehatan untuk semua).

Selanjutnya, pembangunan kesehatan nasional diamanatkan UUD dan perundang-undangan lain. Pertama, UUD 45 Pasal 28 menyatakan : (1) setiap orang berhak hidup sejahtera lahir dan batin, bertempat tinggal, dan mendapatkan lingkungan hidup yang baik dan sehat serta berhak memperoleh pelayanan kesehatan; dan (2) setiap orang berhak atas jaminan sosial yang memungkinkan pengembangan dirinya secara utuh sebagai manusia yang bermartabat. Selain itu, Pasal 34 ayat (1), (2), (3) UUD 1945 menyatakan : (1) Fakir miskin dan anak-anak yang terlantar dipelihara oleh Negara; (2) Negara mengembangkan sistem jaminan sosial bagi seluruh rakyat dan memberdayakan masyarakat yang lemah dan tidak mampu sesuai dengan martabat kemanusiaan; dan (3) Negara bertanggung jawab atas penyediaan fasilitas pelayanan kesehatan dan fasilitas pelayanan umum yang layak. Kedua, pembangunan kesehatan juga diamanatkan dalam perundang-undangan lainnya, antara lain : (1) UU No 40 tahun 2004 tentang Sistem Jaminan Sosial Nasional; (2) UU No.36 Tahun 2009 tentang Kesehatan; (3) UU No. 24 Tahun 2011 tentang Badan Penyelenggara Jaminan Sosial; (4) PP No.101 Tahun 2012 tentang Penerima Bantuan Iuran Jaminan Kesehatan; dan (5) Perpres No 12 Tahun 2013 tentang Jaminan Kesehatan. Regulasi jaminan kesehatan nasional sejalan dengan resolusi World Health Assembly (WHA) mengenai Universal Health Coverage (UHC) yang telah disepakati secara internasional termasuk Indonesia.

Kebijakan jaminan kesehatan dalam mewujudkan Universal Health Coverage (UHC) diharapkan mampu meningkatkan derajat kesehatan masyarakat di Indonesia. Menurut Murti dkk (2011), kondisi pembangunan kesehatan di Indonesia relatif tertinggal dibandingkan dengan negara-negara lain di Asia Tenggara.

Guna meningkatkan pembangunan dan derajat kesehatan masyarakat, pemerintah telah mengimplementasikan kebijakan jaminan kesehatan mulai Tahun 2014, yang secara teknis diatur dalam Perpres Nomor 12 Tahun 2013 tentang Jaminan Kesehatan. Regulasi jaminan kesehatan merupakan wujud dari upaya pelaksanaan Universal Health Coverage (UHC). Permasalahannya 
adalah apakah kebijakan jaminan kesehatan tersebut sudah diimplementasikan dengan baik. Tujuan penelitian ini adalah menganalisis implementasi kebijakan jaminan kesehatan bagi masyarakat miskin di Kabupaten Pati.

\section{TINJAUAN PUSTAKA}

\section{Universal Health Coverage}

Stuckler et al (2010) menyampaikan bahwa Universal Health Coverage (UHC) merupakan inklusi penjaminan kesehatan yang diterapkan bagi negara berpendapatan rendah dan menengah. Tujuan Universal Health Coverage adalah menyediakan semua warga negara memiliki asuransi pelayanan kesehatan. Semua orang memiliki asuransi dan akses pada pelayanan kesehatan. Universal Health Coverage memiliki konotasi $100 \%$ coverage (kepesertaan) penduduk dalam perencanaan kesehatan inklusi dalam kepesertaan kesehataan yang komprehensif. Pelaksanaan Universal Health Coverage menjadi bervariasi antara negara satu dengan negara lainnya. Namun apapun wujud Universal Health Coverage bertolak dari resolusi World Health Assembly (WHA).

World Health Assembly (WHA) Tahun 2005 memiliki sejumlah resolusi diantaranya mendesak para negara anggota: (1) menjamin sistem pendanaan kesehatan termasuk metode bagi pembayaran kontribusi perawatan kesehatan, dengan memandang berbagi risiko antar penduduk; (2) menjamin distribusi sarana dan SDM kesehatan yang cukup dan merata bagi pelayanan kesehatan yang baik; (3) merencanakan transisi Universal Health Coverage bagi warga/penduduk sehingga berkontribusi terhadap perawatan kesehatan penduduk dan untuk mencapai kesehatan bagi semua (health for all); (4) mengakui bahwa pengelolaan Universal Health Coverage, merupakan opsi yang dikembangkan sesuai dengan kondisi makro ekonomi, kultur sosial dan konteks politik masing-masing negara; (5) mengambil peluang, bila memungkinkan bahwa kolaborasi antara penyedia layanan publik (negara) dan swasta dan keorganisasian pendanaan kesehatan berada dibawah kendali lembaga pemerintah; dan (6) Berbagi pengalaman dari berbagai metode pendanaan kesehatan termasuk skema pengembangan asuransi sosial kesehatan, dan skema kombinasi asuransi perorangan dan asuransi publik dengan cara tertentu yang diarahkan pada sistem pendanaan kesehatan. Relevan hal tersebut, Indonesia komitment dan mencanangkan kebijakan jaminan kesehatan.

\section{Kebijakan Jaminan Kesehatan}

Kebijakan menurut Nugroho (2006) adalah segala sesuatu yang dikerjakan pemerintah, mengapa mereka melakukan dan hasil apa yang membuat kehidupan bersama tampil berbeda. Menurut Raksasataya dalam Islami (2001), kebijakan merupakan suatu taktik dan strategi yang diarahkan untuk mencapai tujuan. Kebijakan memuat tiga elemen pokok : (1) identifikasi dari tujuan yang ingin dicapai, (2) taktik dan 
strategi dari berbagai langkah untuk mencapai tujuan yang diinginkan, (3) penyediaan berbagai masukan untuk memungkinkan pelaksanaan secara nyata dari taktik atau strategi kebijakan.

Ada implikasi dalam konsep kebijakan negara yaitu : (1) kebijakan lebih merupakan tindakan yang mengarah pada tujuan dari pada perilaku atau tindakan; (2) kebijakan hakekatnya terdiri atas tindakan yang saling terkait dan berpola yang mengarah pada tujuan tertentu yang dilakukan oleh pejabat pemerintah dan bukan merupakan keputusan yang berdiri sendiri; dan (3) kebijakan bersangkut paut dengan apa yang senyatanya dilakukan pemerintah dalam bidang tertentu (Wahab, 2001).

Proses tahapan kebijakan menurut Anderson dalam Subarsono (2005) mencakup : (1) penetapan agenda kebijakan (agenda setting), menentukan masalah publik yang perlu untuk dipecahkan. (2) formulasi kebijakan (policy formulation), mengidentifikasikan kemungkainan kebijakan yang mungkin digunakan dalam memecahkan masalah. (3) adopsi kebijakan (policy adoption), menentukan pilihan kebijakan melalui dukungan para administrator dan legislatif. Tahap ini ditentukan melalui suatu proses rekomendasi. implementasi kebijakan (policy implementation), suatu tahap dimana kebijakan yang telah diadopsi dilaksanakan oleh unit-unit tertentu dengan memobilisasi dana dan sumber daya yang ada. (5) penilaian kebijakan (policy assessment).

Kebijakan jaminan kesehatan secara teknis diatur dalam Perpres
Nomor 12 Tahun 2013. Pengertian "Jaminan Kesehatan" menurut Perpres Nomor 12 Tahun 2013 adalah jaminan berupa perlindungan kesehatan agar peserta memperoleh manfaat pemeliharaan kesehatan dan perlindungan dalam memenuhi kebutuhan dasar kesehatan yang diberikan kepada setiap orang yang telah membayar iuran atau iurannya dibayar oleh pemerintah.

Peserta jaminan kesehatan nasional dapat dibedakan asal iurannya yaitu : (1) Penerima Bantuan Iuran (PBI) jaminan kesehatan; dan (2) Bukan Penerima Bantuan Iuran (Non PBI) Jaminan Kesehatan. Peserta PBI jaminan kesehatan meliputi orang yang tergolong fakir miskin dan orang tidak mampu. Peserta bukan PBI jaminan kesehatan merupakan peserta yang tidak tergolong fakir miskin dan orang tidak mampu.

\section{Implementasi Kebijakan}

Implementasi kebijakan menurut Grindle (1980), merupakan proses umum tindakan administraiif yang dapat diteliti pada tingkat program tertentu. Implementasi kebijakan sangat ditentukan oleh isi kebijakan (content of policy) dan konteks kebijakan (context of policy). Pertama, isi kebijakan (content of policy) mencakup (a) kepentingan yang terpengaruhi oleh kebijakan, (b) jenis manfaat yang akan dihasilkan, (c) derajat perubahan yang akan diinginkan, (d) kedudukan pembuat kebijakan, (e) siapa pelaksana program, dan (f) sumberdaya yang dikerahkan. Kedua, konteks kebijakan (context of policy) mencakup : (a) kekuasaan, kepentingan 
dan strategi aktor yang terlibat, (b) karakteristik lembaga dan penguasa, dan (c) kepatuhan serta daya tangkap pelaksana terhadap kebijakan. Kebijakan yang menyangkut banyak kepentingan yang berbeda lebih sulit diimplementasikan dibandingkan kebijakan yang menyangkut sedikit kepentingan. Intensitas keterlibatan berbagai pihak (politisi, pengusaha, masyarakat, kelompok sasaran dan sebagainya) dalam implementasi kebijakan akan berpengaruh terhadap efektivitas implementasi kebijakan.

\section{METODE PENELITIAN}

Penelitian ini menggunakan pendekatan deskriptif-kuantitatif. Lokus penelitian berada di Kabupaten Pati. Variabel penelitian mencakup : (1) coverage PBI jaminan kesehatan; dan (2) distribusi PBI jaminan kesehatan. Data penelitian meliputi data skunder dan data primer. Data skunder dikumpulkan dengan observasi dokumen. Data primer dikumpulkan dengan teknik wawancara pada narasumber dari Dinas Kesehatan Pati dan informan dari masyarakat. Teknik analisis data dalam penelitian ini menggunakan análisis deskriptif dan analisis korelatif. Secara teknis, analisis data menggunakan rumus :

\section{1). Coverage PBI Jaminan kesehatan}

$$
\mathrm{CPBI}=\mathrm{PBI} / \mathrm{PM}
$$

Keterangan :

$$
\begin{aligned}
\text { CPBI = } & \text { Coverage penerima bantuan } \\
& \text { iuran jamkes } \\
\text { PBI = } & \text { Jumlah peserta bantuan iuran } \\
& \text { jamkes }
\end{aligned}
$$

$\mathrm{PM}=$ Jumlah penduduk miskin (pra sejahtera)

\section{2). Korelasi PBI Jamkes terhadap Eksistensi Kemiskinan}

$\mathbf{P}=1-\frac{6 \sum b i^{2}}{n\left(n^{2}-1\right)}$

Keterangan :

$\mathrm{P}=$ rho (nilai hitung spearman rank)

$\mathrm{n}=$ jumlah sampel yang dibandingkan

bi= beda ranking $\mathrm{i}$

\section{3). Disparitas Distribusi PBI Jamkes}

$\mathrm{G}=1-2 Z$

$\mathrm{G}=$ Indeks Gini

$\mathrm{Z}=$ luas area Kurva Lorenz

\section{HASIL DAN PEMBAHASAN}

Jaminan Kesehatan menurut Perpres Nomor 12 Tahun 2013 adalah jaminan berupa perlindungan kesehatan agar peserta memperoleh manfaat pemeliharaan kesehatan dan perlindungan dalam memenuhi kebutuhan dasar kesehatan yang diberikan kepada setiap orang yang telah membayar iuran atau iurannya dibayar oleh pemerintah. Penerima Bantuan Iuran (PBI) jaminan kesehatan meliputi orang yang tergolong fakir miskin dan orang tidak mampu. Fakir Miskin adalah orang yang sama sekali tidak mempunyai sumber mata pencaharian dan/atau mempunyai sumber mata pencaharian tetapi tidak mempunyai kemampuan memenuhi kebutuhan dasar yang layak bagi kehidupan dirinya dan/atau keluarganya. Kemudian "Orang Tidak Mampu" adalah orang yang mempunyai sumber mata pencaharian, gaji atau upah, 
yang hanya mampu memenuhi kebutuhan dasar yang layak namun tidak mampu membayar iuran bagi dirinya dan keluarganya.

\section{Eksistensi Penduduk Miskin dan Orang Tidak Mampu}

Eksistensi fakir miskin/orang tidak mampu dalam studi ini diukur dengan menggunakan parameter keluarga prasejahtera (BPPKB, 2016). Kabupaten Pati memiliki jumlah penduduk 1.371.052 orang dan 424.616 KK, berarti rerata setiap KK adalah 3,23 orang. Keluarga (KK) yang masuk kategori keluarga prasejahtera sebanyak 132.129 KK $(31,12 \%)$ maka penduduk miskin sebanyak 426.634 orang (132.129 KK kali 3,23 orang).

Kondisi kemiskinan (fakir miskin/orang tidak mampu) yang paling tinggi berada di Kecamatan Pucakwangi dengan tingkat kemiskinan (52,93\%). Jumlah penduduk Kecamatan Pucakwangi 51.102 orang (15.690 KK) sehingga rerata KK sebesar 3,26 orang. Jumlah keluarga yang masuk kategori keluarga prasejahtera sebanyak 8.305 KK maka jumlah penduduk yang masuk kategori fakir miskin/orang tidak mampu sebanyak 27.049 orang yang berasal dari 8.305 x 3,26. Kondisi kemiskinan dan orang tidak mampu di Kabupaten Pati Tahun 2015 ditunjukkan Tabel 1.

Tabel 1.

Eksistensi Penduduk Miskin dan Orang Tidak Mampu di Kabupaten Pati

\begin{tabular}{rlrrrrr}
\hline No & \multicolumn{1}{c}{ Kecamatan } & $\begin{array}{c}\text { Jumlah } \\
\text { Penduduk }\end{array}$ & $\begin{array}{c}\text { Jumlah } \\
\text { KK }\end{array}$ & $\begin{array}{c}\text { Rerata } \\
\text { Org/KK }\end{array}$ & $\begin{array}{c}\text { KK } \\
\text { Prasejahtera }\end{array}$ & $\begin{array}{c}\text { Penduduk } \\
\text { Miskin }\end{array}$ \\
\hline 1 & Sukolilo & 91.082 & 28.951 & 3,15 & 9.347 & 29.406 \\
2 & Kayen & 80.878 & 24.085 & 3,36 & 5.814 & 19.524 \\
3 & Tambakromo & 58.672 & 17.136 & 3,42 & 7.736 & 26.487 \\
4 & Winong & 69.711 & 22.681 & 3,07 & 11.061 & 33.996 \\
5 & Pucakwangi & 51.102 & 15.690 & 3,26 & 8.305 & 27.049 \\
6 & Jaken & 49.530 & 15.572 & 3,18 & 6.525 & 20.754 \\
7 & Batangan & 47.509 & 15.006 & 3,17 & 5.445 & 17.239 \\
8 & Juwana & 94.981 & 29.704 & 3,20 & 8.194 & 26.201 \\
9 & Jakenan & 49.182 & 16.918 & 2,91 & 6.864 & 19.954 \\
10 & Pati & 107.287 & 32.326 & 3,32 & 5.413 & 17.965 \\
11 & Gabus & 66.423 & 19.861 & 3,34 & 5.413 & 18.103 \\
12 & Margorejo & 60.861 & 19.238 & 3,16 & 2.808 & 8.883 \\
13 & Gembong & 50.723 & 14.782 & 3,43 & 5.607 & 19.240 \\
14 & Tlogowungu & 56.021 & 17.931 & 3,12 & 5.323 & 16.630 \\
15 & Wedarijaksa & 65.350 & 20.538 & 3,18 & 6.880 & 21.892 \\
16 & Trangkil & 69.253 & 20.878 & 3,32 & 6.688 & 22.184 \\
17 & Margoyoso & 77.167 & 23.279 & 3,31 & 4.999 & 16.571 \\
18 & Gunungwungkal & 40.231 & 12.269 & 3,28 & 3.211 & 10.529 \\
19 & Cluwak & 51.917 & 16.118 & 3,22 & 4.472 & 14.405 \\
20 & Tayu & 71.101 & 22.222 & 3,20 & 5.512 & 17.636 \\
21 & Dukuhseti & 62.071 & 19.431 & 3,19 & 6.512 & 20.802 \\
\hline & Kabupaten Pati & 1.371 .052 & 424.616 & 3,23 & 132.129 & 426.634 \\
\hline
\end{tabular}

Sumber : BPPKB (2016), data diolah 


\section{Coverage Bantuan Iuran Jaminan} Kesehatan

Bantuan iuran jaminan kesehatan diarahkan pada penduduk miskin dan kurang mampu. Besarnya coverage bantuan iuran jaminan kesehatan dapat diukur dengan perbandingan (ratio) antara jumlah penerima bantuan iuran jaminan kesehatan terhadap jumlah penduduk yang masuk kategori miskin dan atau kurang mampu.

Kecamatan Sukolilo misalnya memiliki penduduk miskin sebanyak 29.406 orang dan penerima bantuan iuran jaminan kesehatan (PBI Jamkes) sebanyak 60.264 orang. Ini berarti, ratio coverage bantuan iuran jaminan kesehatan terhadap penduduk miskin sebesar 2,05 yang berasal dari 60.264 dibagi 29.406. Kecamatan Sukolilo memiliki 16 desa. Coverage bantuan iuran jaminan kesehatan terbesar berada di Desa Kasiyan yaitu 4,10 dan coverage bantuan iuran jaminan kesehatan terkecil berada di Desa Baleadi yaitu 0,94 . Coverage bantuan iuran jaminan kesehatan di Kabupaten Pati ditunjukkan pada Tabel 2 .

Tabel 2.

Coverage Bantuan Iuran Jaminan Kesehatan terhadap Penduduk Miskin

\begin{tabular}{|c|c|c|c|c|c|c|c|c|c|}
\hline \multirow[t]{2}{*}{ No } & \multirow[t]{2}{*}{ Kecamatan } & \multirow{2}{*}{$\begin{array}{l}\text { Penduduk } \\
\text { Miskin }\end{array}$} & \multirow{2}{*}{$\begin{array}{c}\text { PBI } \\
\text { Jamkes }\end{array}$} & \multicolumn{3}{|c|}{ Ratio Coverage PBI } & \multirow{2}{*}{$\begin{array}{l}\text { Jml } \\
\text { Desa }\end{array}$} & \multirow{2}{*}{$\begin{array}{c}\text { Ratio } \\
\geq 1\end{array}$} & \multirow{2}{*}{$\begin{array}{l}\text { Ratio } \\
<1\end{array}$} \\
\hline & & & & Rata & Maks & Min & & & \\
\hline 1 & Sukolilo & 29.406 & 60.264 & 2,05 & 4,10 & 0,94 & 16 & 15 & 1 \\
\hline 2 & Kayen & 19.524 & 57.369 & 2,94 & 5,02 & 1,89 & 17 & 17 & 0 \\
\hline 3 & Tambakromo & 26.487 & 32.119 & 1,21 & 2,02 & 0,64 & 18 & 13 & 5 \\
\hline 4 & Winong & 33.996 & 30.753 & 0,90 & 1,98 & 0,49 & 30 & 12 & 18 \\
\hline 5 & Pucakwangi & 27.049 & 30.834 & 1,14 & 2,75 & 0,70 & 20 & 13 & 7 \\
\hline 6 & Jaken & 20.754 & 37.104 & 1,79 & 2,35 & 1,10 & 21 & 21 & 0 \\
\hline 7 & Batangan & 17.239 & 31.032 & 1,80 & 4,40 & 1,16 & 18 & 18 & 0 \\
\hline 8 & Juwana & 26.201 & 63.083 & 2,41 & 6,88 & 1,10 & 29 & 29 & 0 \\
\hline 9 & Jakenan & 19.954 & 29.210 & 1,46 & 2,52 & 0,55 & 23 & 17 & 6 \\
\hline 10 & Pati & 17.965 & 47.562 & 2,65 & 4,04 & 1,51 & 29 & 29 & 0 \\
\hline 11 & Gabus & 18.103 & 31.525 & 1,74 & 3,23 & 0,71 & 24 & 23 & 1 \\
\hline 12 & Margorejo & 8.883 & 26.234 & 2,95 & 6,38 & 1,69 & 18 & 18 & 0 \\
\hline 13 & Gembong & 19.240 & 30.230 & 1,57 & 2,25 & 0,56 & 11 & 10 & 1 \\
\hline 14 & Tlogowungu & 16.630 & 38.751 & 2,33 & 4,53 & 1,49 & 15 & 15 & 0 \\
\hline 15 & Wedarijaksa & 21.892 & 45.554 & 2,08 & 3,89 & 1,13 & 18 & 18 & 0 \\
\hline 16 & Trangkil & 22.184 & 43.342 & 1,95 & 3,24 & 1,22 & 16 & 16 & 0 \\
\hline 17 & Margoyoso & 16.571 & 49.799 & 3,01 & 9,80 & 1,11 & 22 & 22 & 0 \\
\hline 18 & Gunungwungkal & 10.529 & 21.006 & 2,00 & 3,33 & 0,76 & 15 & 14 & 1 \\
\hline 19 & Cluwak & 14.405 & 37.692 & 2,62 & 4,39 & 1,79 & 13 & 13 & 0 \\
\hline 20 & Tayu & 17.636 & 46.874 & 2,66 & 5,73 & 1,11 & 21 & 21 & 0 \\
\hline 21 & Dukuhseti & 20.802 & 39.152 & 1,88 & 3,17 & 1,21 & 12 & 12 & 0 \\
\hline & Kabupaten Pati & 426.634 & 829.489 & 1,95 & 3,01 & 0,90 & 406 & 366 & 40 \\
\hline
\end{tabular}

Sumber : Pengolahan Data (2016)

Berdasarkan Tabel 2, ada indikasi ketimpangan dalam coverage bantuan iuran jaminan kesehatan. Rerata coverage terbesar berada di Kecamatan 
Margoyoso dengan ratio coverage bantuan iuran jaminan kesehatan sebesar 3,01 dan coverage terkecil berada di Kecamatan Winong dengan rerata ratio 0,90 .

Kecamatan Margoyoso memiliki 22 desa dengan jumlah penduduk sebanyak 77.167 orang dan 23.279 KK. Ini berarti rerata setiap keluarga (KK) sebesar 3,31. Keluarga yang masuk kategori keluarga prasejahtera sebanyak 4.999 KK (BPPKB, 2016), maka penduduk miskin sebanyak 16.571 orang yang berasal dari 4.999 kali 3,31. Kecamatan Margoyoso memiliki 22 desa dan kumulatif penerima bantuan iuran (PBI) jaminan kesehatan sebanyak 49.799 orang. Ini berarti ratio coverage bantuan iuran jaminan kesehatan terhaadap penduduk miskin/kurang mampu sebesar 3,01 (49.799/16.571) atau proporsi bantuan iuran jaminan kesehatan sebesar $301 \%$ dari jumlah penduduk miskin. Coverage bantuan iuran jaminan kesehatan terbesar berada di Desa Ngemplak kidul dengan ratio 9,80 dan coverage bantuan iuran jaminan kesehatan terkecil berada di Desa Langgenharjo dengan ratio 1,11.

Selanjutnya, Kecamatan Winong memiliki ratio coverage terkecil dengan rerata ratio 0,90 . Kecamatan Winong memiliki penduduk sebanyak 69.711 orang dan 22.681 KK. Ini berarti rerata setiap keluarga (KK) sebesar 3,07. Keluarga yang masuk kategori keluarga prasejahtera sebanyak $11.061 \mathrm{KK}$ maka penduduk miskin dan kurang mampu 33.996 orang yang berasal dari 11.061 kali 3,07.
Kecamatan Winong memiliki 30 desa dan jumlah penerima bantuan iuran (PBI) jaminan kesehatan sebanyak 30.753 orang. Ini berarti ratio coverage bantuan iuran jaminan kesehatan sebesar 0,90 (30.753/33.996). Untuk coverage bantuan iuran jaminan kesehatan terbesar berada di Desa Pohgading yaitu 1,98 dan untuk coverage bantuan iuran jaminan kesehatan terkecil berada di Desa Kropak yaitu 0,49 .

\section{Keadilan Distribusi Bantuan Iuran Jaminan Kesehatan}

Bantuan iuran jaminan kesehatan seharusnya didistribusikan dengan adil dengan memperhatikan tingkat kebutuhan, eksistensi kemiskinan. Kawasan yang memiliki penduduk miskin terbanyak seharusnya juga memperoleh posting bantuan iuran jaminan kesehatan paling banyak sehingga ada korelasi antara ketersediaan bantuan iuran jaminan kesehatan terhadap kebutuhan. Guna menguji korelasi antara kebutuhan dan ketersediaan bantuan iuran jaminan kesehatan akan digunakan alat uji statistik Spearman Rank Correlation.

Berdasarkan persamaan no. 2, kebutuhan bantuan iuran jaminan kesehatan dan ketersediaan bantuan iuran jaminan kesehatan dapat dikonversi menjadi urutan ranking. Kebutuhan bantuan iuran jaminan kesehatan ditunjukkan dengan eksistensi penduduk miskin. Ketersediaan bantuan iuran jaminan kesehatan ditunjukkan dengan eksistensi penerima bantuan iuran (PBI) jaminan kesehatan. Guna menguji 
distribusi bantuan iuran jaminan kesehatan berbasis keadilan maka penduduk miskin dan penerima bantuan iuran (PBI) jaminan kesehatan dikonversi menjadi ranking. Kecamatan Kayen misalnya, memiliki penduduk miskin 19.524 menempati ranking 11 dari urutan terbesar 21 kecamatan. Disisi lain, Kecamatan Kayen memiliki penduduk yang menjadi penerima bantuan iuran (PBI) jaminan kesehatan sebanyak 57.369 orang menempati ranking 3 dari urutan terbesar. Semua kawasan tingkat kebutuhan dan ketersediaan bantuan iuran jaminan kesehatan di konversi ke dalam ranking dan dicari nilai beda ranking kemudian dihitung nilai kuadratnya. Konversi penduduk miskin dan penerima bantuan iuran (PBI) jaminan kesehatan menjadi ranking untuk analisis Spearman Rank Correlation ditunjukkan dalam Tabel 3.

Berdasarkan rumus diatas nilai Rho,

$$
\begin{aligned}
\mathrm{P} & =1-\left(\left(6 \cdot \Sigma \mathrm{bi}^{2}\right) / \mathrm{n}\left(\mathrm{n}^{2}-1\right)\right) \\
& =1-\left((6 \times 1192) / 21\left(21^{2}-1\right)\right) \\
\mathrm{P} & =1-(7152 / 9240) \\
& =1-0,774 \\
& =0,226 \text { (nilai rho hitung) }
\end{aligned}
$$

Tabel 3.

Korelasi Bantuan Iuran Jaminan Kesehatan terhadap Penduduk Miskin

\begin{tabular}{rlrrrrrc}
\hline No & Kecamatan & $\begin{array}{c}\text { Penduduk } \\
\text { Miskin }\end{array}$ & $\begin{array}{c}\text { Rank } \\
\text { (Xi) }\end{array}$ & $\begin{array}{c}\text { PBI } \\
\text { Jamkes }\end{array}$ & $\begin{array}{c}\text { Rank } \\
\text { (Yi) }\end{array}$ & $\begin{array}{c}\text { Beda } \\
\text { (bi) }\end{array}$ & $\begin{array}{c}\text { Beda Kw } \\
\text { (bi x bi) }\end{array}$ \\
\hline 1 & Sukolilo & 29.406 & 2 & 60.264 & 2 & 0 & 0 \\
2 & Kayen & 19.524 & 11 & 57.369 & 3 & 8 & 64 \\
3 & Tambakromo & 26.487 & 4 & 32.119 & 13 & -9 & 81 \\
4 & Winong & 33.996 & 1 & 30.753 & 17 & -16 & 256 \\
5 & Pucakwangi & 27.049 & 3 & 30.834 & 16 & -13 & 169 \\
6 & Jaken & 20.754 & 9 & 37.104 & 12 & -3 & 9 \\
7 & Batangan & 17.239 & 16 & 31.032 & 15 & 1 & 1 \\
8 & Juwana & 26.201 & 5 & 63.083 & 1 & 4 & 16 \\
9 & Jakenan & 19.954 & 10 & 29.210 & 19 & -9 & 81 \\
10 & Pati & 17.965 & 14 & 47.562 & 5 & 9 & 81 \\
11 & Gabus & 18.103 & 13 & 31.525 & 14 & -1 & 1 \\
12 & Margorejo & 8.883 & 21 & 26.234 & 20 & 1 & 1 \\
13 & Gembong & 19.240 & 12 & 30.230 & 18 & -6 & 36 \\
14 & Tlogowungu & 16.630 & 17 & 38.751 & 10 & 7 & 49 \\
15 & Wedarijaksa & 21.892 & 7 & 45.554 & 7 & 0 & 0 \\
16 & Trangkil & 22.184 & 6 & 43.342 & 8 & -2 & 4 \\
17 & Margoyoso & 16.571 & 18 & 49.799 & 4 & 14 & 196 \\
18 & Gunungwungkal & 10.529 & 20 & 21.006 & 21 & -1 & 1 \\
19 & Cluwak & 14.405 & 19 & 37.692 & 11 & 8 & 64 \\
20 & Tayu & 17.636 & 15 & 46.874 & 6 & 9 & 81 \\
21 & Dukuhseti & 20.802 & 8 & 39.152 & 9 & -1 & 1 \\
\hline & E (bi x bi) & & & & & & 1192 \\
\hline
\end{tabular}

Sumber : Pengolahan Data (2016)

Nilai Rho tabel $\mathrm{n}=21$ dengan toleransi kesalahan $5 \%$ sebesar 0,439 .
Nilai Rho hitung $(0,226)$ lebih kecil dari nilai Rho tabel $(0,439)$ yang berarti tidak 
ada kesesuaian antara tingkat ranking kebutuhan bantuan iuran jaminan kesehatan bagi penduduk miskin dengan tingkat ranking penerima bantuan iuran (PBI) jaminan kesehatan. Ini berarti ada indikasi ketidakadilan dalam distribusi bantuan iuran jaminan kesehatan.

\section{KESIMPULAN DAN SARAN}

\section{Kesimpulan}

1. Coverage bantuan iuran jaminan kesehatan bagi penduduk miskin di Kabupaten Pati memenuhi batas kecukupan minimal dengan status ratio coverage 1,95 (195\%).

2. Coverage bantuan iuran jaminan kesehatan anatar kawasan mengalami timpangan dengan ratio coverage terbesar 3,01 (301\%) dan ratio coverage terkecil 0,90 (90\%).

3. Keadilan distribusi bantuan iuran jaminan kesehatan relatif kurang baik yang ditunjukkan uji statistik Spearman Rank Correlation dengan nilai Rho hitung $(0,226)$ lebih kecil dari nilai Rho tabel $(0,439)$ yang berarti tidak ada kesesuaian antara tingkat kebutuhan bantuan iuran jaminan kesehatan bagi penduduk miskin dengan penerima bantuan iuran (PBI) jaminan kesehatan.

\section{Saran}

Dinas/instansi yang memiliki otoritas dalam implementasi kebijakan jaminan kesehatan agar mengambil 5 tindakan perbaikan :

1. Terdapat indikasi terjadi pencatatan ganda (double recording). Guna mereduksi masalah double recording perlu ada pendataan ulang dengan mencantumkan informasi utama: (1) nama; (2) tempat tanggal lahir; (3) Nomor Induk Kependudukan; (4) No Kepesertaan Jamkes; dan (5) Alamat.

2. Guna mereduksi ketimpangan antar kawasan maka penerima bantuan iuran jaminan kesehatan yang tercatat ganda agar dialihkan pada kawasan lain yang memiliki ratio coverage kecil.

3. Desa dengan penerima bantuan iuran (PBI) jaminan kesehatan berlebihan (nilai ratio caverage besar) agar dilakukan assessment ekonomi/sosial, karena ada indikasi sebagian penduduk yang masuk kategori mampu (tidak miskin) ikut menikmati bantuan iuran jaminan kesehatan yang disediakan bagi penduduk miskin. Sisi lain, ada desa sebagian penduduk yang masuk kategori miskin tidak memperoleh bantuan iuran jaminan kesehatan yang ditunjukkan nilai ratio coverage lebih kecil dari 1,0.

4. Penyesuaian antara tingkat kebutuhan bantuan iuran jaminan kesehatan bagi penduduk miskin dengan tingkat kondisi penerima bantuan iuran (PBI) jaminan kesehatan.

5. Memperbaiki tata kelola bantuan iuran jaminan kesehatan dengan membentuk tim yang melibatkan dinas/instansi yang relevan dan atau memiliki kapasitas untuk pembenahan pendataan dan tata kelola bantuan iuran jaminan kesehatan yang berasumber dari APBN, APBD Propinsi dan APBD Kabupaten. 


\section{DAFTAR PUSTAKA}

Badan Pemberdayaan Perempuan dan Keluarga Berencana. (2016). Hasil Pendataan Keluarga Tahun 2016. Pati.

Grindle, M. S. (1980). Politics and Policy Implementation in the Third World. New Jersey : Princeton University Press.

Islamy, M. I. (1988). Prinsip-Prinsip Perumusan Kebijaksanaan

Negara. Jakarta : Penerbit Bina Aksara.

Murti, B., Hadinoto, S. H., Herlambang, G. (2011). Ketrampilan Kedokteran Keluarga: Kunjungan Pasien di Rumah. Modul Fakultas Kedokteran. Surakarta : Universitas Sebelas Maret.

Nugroho, R. (2006). Kebijakan Publik Untuk Negara-Negara Berkembang. Jakarta : Gramedia.

Peraturan Pemerintah Republik Indonesia Nomor 101 Tahun 20I2 tentang Penerima Bantuan Iuran Jaminan.

Peraturan Presiden Republik Indonesia Nomor 12 Tahun 2013 tentang Jaminan Kesehatan.

Stuckler, David, A., Feigl, S., Basu. M., McKee. (2010). The Political Economy of Universal Health Coverage. The Global Symposium on Health Systems Research 16-19 November 2010. Montreux, Switzerland
Subarsono, A. G. (2005). Analisis Kebijakan Publik : Teori dan Aplikasi. Yogyakarta : Pustaka Pelajar.

Undang-Undang Dasar Negara Republik Indonesia Tahun 1945

Undang-Undang Republik Indonesia Nomor 40 Tahun 2004 tentang Sistem Jaminan Sosial Nasional.

Undang-Undang Republik Indonesia Nomor 36 Tahun 2009 tentang Kesehatan.

Undang-Undang Republik Indonesia Nomor 24 Tahun 2011 tentang Badan Penyelenggara Jaminan Sosial.

United Nations. (2000). Indicators for Monitoring the Millenium Development Goals. New York : UNDP.

Wahab, S. A. (2001). Analisis Kebijakan: Dari Formulasi Ke Implementasi Kebijaksanaan Negara. Jakarta : Bumi Aksara.

World Health Organization. (2005). Fifty Eighty World Health Assembly. Geneva : World Health Organization.

\section{BIODATA PENULIS}

Suroso, lahir 19 Maret 1966 di Kabupaten Pati Jawa Tengah. Magister Perencanaan Kota dan Daerah Universitas Gajah Mada. Bekerja di Badan Perencanaan Pembangunan Daerah Kabupaten Pati sebagai Peneliti Madya. 